\title{
De bijdrage van de accountant aan het voorkomen en bestrijden van corruptie
}

\author{
Drs. A.J.E. Jansman
}

\section{Inleiding ${ }^{1}$}

Corruptie kan worden omschreven als het misbruik van positie en kennis door functionarissen in de publieke en private sector met het doel daaruit financieel voordeel te behalen.

Met betrekking tot corruptie en de betekenis van dit fenomeen voor de accountant in zijn controlerende en adviserende functie bestaat nog weinig literatuur. Dit is opvallend daar corruptie een voor de accountant relevant maatschappelijk verschijnsel is. Corruptie kan immers daar optreden waar controlesystemen niet adequaat zijn opgezet dan wel onvoldoende werken. Het bestaan van corruptie heeft zelfs bijgedragen aan de ontwikkeling van het accountantsberoep. Corrupt handelen door de leiding wordt door fatsoenlijke eigenaren van ondernemingen niet geaccepteerd. Deze eigenaren maken gebruik van de diensten van accountants om meer zekerheid te krijgen omtrent de vraig of de leiding corrupt heeft gehandeld. Deze attitude van de eigenaren ten opzichte van corruptie is minder vanzelfsprekend dan zij op het eerste gezicht lijkt; eigenaren kunnen immers ook financiële voordelen halen uit corruptie. Een voorbeeld daarvan is de betaling van steekpenningen aan potentiële opdrachtgevers.

Het ontbreken van literatuur en statistische gegevens omtrent de aard en omvang van de uit corruptie voortvloeiende maatschappelijke schade hangt samen met de aard van corruptie: het speelt zich af in het informele gedeelte van het economisch leven.

Het onderzoek naar corruptie is in het verleden voomamelijk gericht geweest op corruptie in de publieke sector. Beperking van het onderzoek naar corruptie tot de publieke sector doet geen recht aan de maatschappelijke realiteit; corruptie in de publieke sector is in de meeste gevallen slechts mogelijk als er een vorm van samenwerking plaatsvindt tussen publieke en private sector. Ook binnen de private sector als zodanig treedt corruptie op; samenspanning tussen inkoper en leverancier is hiervan een voorbeeld. De maatschappelijke relevantie van corruptie wordt versterkt door de invloed van de georganiseerde criminaliteit. De financiële belangen van criminele organisaties zijn vaak zo aanzienlijk dat zij grote druk uitoefenen op de publieke en private sector corruptie te accepteren of zelfs over te gaan tot corrupt gedrag.

Het belang van de deskundigheid op het gebied van de opzet van controlesystemen en de uitvoering van controlewerkzaamheden die door accountants kan worden ingebracht in de strijd tegen corruptie vormt onderwerp van dit artikel.

Het zou echter een illusie zijn te veronderstellen dat adequate controlesystemen en controlewerkzaamheden corruptie in het geheel kunnen uitschakelen. De beslissing van een individu of een groep van individuen zich corrupt te gedragen is bovenal een probleem van integriteit. Dit gegeven alsmede de tussen individuele landen bestaande verschillen in aard, omvang en maatschappelijke perceptie van corruptie stelt eisen aan de opzet van het onderzoek naar corruptiebestrijding. Een multidisciplinaire benadering, waarbij juristen, antropologen, economen en technische wetenschappers hun deskundigheid inbrengen ligt daarbij voor de hand.

Drs. A.J.E. Jansman is vennoot van Coopers \& Lybrand Accountants en docent in de leer van de accountantscontrole aan de Rijksuniversiteit Groningen. 


\section{Corruptie: een nadere beschouwing}

Corruptie is een verschijnsel dat zich in velerlei vormen voordoet. Te noemen zijn onkoping van potentiële opdrachtgevers en het op oneigenlijke gronden verstrekken en verkrijgen van subsidies. Ook de benoeming van niet capabele, bevriende, personen in bepaalde functies valt in de termen van de hiervoor gegeven definitie van corruptie. Hierna wordt ingegaan op factoren die van invloed kunnen zijn op de aard en omvang van corruplie.

Deze factoren zijn:

- waarden en normen:

- economische situatie;

- organisatie van de publieke sector:

- management in de private sector:

- invloed van de georganiseerde criminaliteit.

\section{a Waarden en normen}

De waarden en normen binnen een samenleving zijn bepalend voor de vraag in hoeverre corruptie binnen die samenleving als een probleem wordt ervaren. Uit onderzoek naar de maatschappelijke perceptie van corruptie in ontwikkelingslanden die na de Tweede Wereldoorlog zelfstandig werden is gebleken dat de economisch zwakkeren berusten in het bestain van corruptie; zij bekommeren zich slechts om hun primaire levensbehoeften. Corruptie bestond reeds gedurende de periode van kolonisatie; de maatschappelijke bovenlaag fungeerde in deze als verlengstuk van de kolonisator. De kolonisator moedigde corruptie zelfs aan on op die wijze de maatschappelijke bovenlaag aan zich te binden. Bij het vertrek van de kolonisator kwam de maatschappelijke bovenlaag aan de macht in een maatschappij waarin corruptie als vanzelfsprekend werd beschouwd.

In Afrikaanse, Zuidamerikaanse en Zuideuropese landen bestaan vaak uitgebreide, op familierelaties gebaseerde. sociale netwerken. Het economisch belang van deze netwerken wordt belingrijker geacht dan het voor velen onvoldoende tastbare malatschappelijk belang. Corruptie uitmondend in voordelen voor een bepaald sociaal netwerk past binnen het stelsel van waarden en normen dat uitgangspunt vormt voor het gedrag van individuen. Door sommige auteurs, walaronder Bayley, wordt opgemerkt dat corruptie ook positieve aspecten heeft. De mogelijkheid in overheidsbetrekking financieel voordeel te behalen uit hoofde van zijn positie, maakt het voor vakinhoudelijk bekwame ambtenaren. ondanks de lage salarissen. aantrekkelijk een functie bij de overheid te aanvalarden. Ook wordt gesteld dat corruptie daar ontstaat waar overheidsinstanties slecht functioneren; corruptie maakt het mogelijk imperfecties in het optreden van overheidsinstanties op te heffen.

\section{b Economische situatie}

Een verslechtering van de economische situatie kan voor individuen en bedrijven aanleiding zijn minder zorgvuldig om te gaan met ethische normen in het kader van de verkrijging en aanvaarding van opdrachten tot levering van goederen en diensten. Ook kunnen tegemoetkomingen van de zijde van de overheid, i.c. subsidies, bepalend zijn voor de overlevingskansen van deelnemers aan het economisch verkeer. Deze omstandigheden versterken de mogelijkheid dat corruptie ontstaat, waarbij ook de samenwerking met criminele organisaties niet kan worden uitgesloten.

\section{c Organisatie van de publicke sector}

De mate waarin de overheid actief participeert in het economisch proces door middel van regelgeving en het verrichten van overheidsuitgaven verschilt per land. De mogelijkheid dat door overheidsfunctionarissen corruptie wordt bedreven treedt in het algemeen daar op waar de publieke sector directe financiële raakvlakken heeft met de private sector. Het zijn juist deze financiële raakvlakken wal het accountantsberoep een rol zou kunnen spelen in de bestrijding van corruptie. Deze raakvlakken betreffen belastingen, subsidies, overheidsinvesteringen en concessies.

Al deze raakvlakken kenmerken zich door een materieel linancieel belang. zowel voor de publie$k e$ als voor de private sector. De regelgeving is vaak zeer complex. Deze complexiteit hangt samen met het streven van de overheid door middel van een bepaalde uitgavencategorie meerdere politieke doelstellingen te realiseren.

\section{d Management in de private sector}

Corruptie brengt in het algemeen met zich mee dat functionarissen uit verschillende organisatics met elkaar moeten samenwerken om het met corruptie beoogde doel te bereiken. Ook in de private sector zal de kans op dergelijke samenwer- 
kingsverbanden toenemen naarmate interne controlesystemen en procedures rond selectie van personeel. opdrachtgevers en afnemers meer gebreken vertonen. Beslissingen waarbij corruptie aan de orde zou kunnen komen worden veelal genomen op hoger managementniveau. Dergelijke beslissingen zullen geen routinematig karakter hebben; gedetailleerde richtlijnen zijn hierbij dan ook niet te verwachten. In dit kader hebben toezichthoudende organen als de Raad van Commissarissen een belangrijke functie. Zij zullen moeten toezien op de mate waarin het management handelt in overeenstemming met ethische normen, te formuleren in samenspraak met datzelfde management. Ook zullen de toezichthoudende organen er zorg voor moeten dragen door de verschillende niveaus in de organisatie geïnformeerd te blijven omtrent het ethisch handelen van het hogere management.

\section{e Invloed van de georganiseerde criminaliteit}

Georganiseerde criminaliteit is een met corruptie sterk verwant verschijnsel. De samenwerkingsverbanden van waaruit criminelen opereren onderscheiden zich nauwelijks van niet-criminele organisaties. Gemeenschappelijke kenmerken zijn ondermeer:

- binnen de organisatie zijn de financierings-, inkoop-, opslag-, verkoop- en transportfunctie te onderkennen;

- internationale vertakkingen;

- meerdere produkten en afzetmarkten.

In hun bedrijfsvoering maken criminele organisaties gebruik van diensten die door derden worden aangeboden. Nadrukkelijk zij vastgesteld dat het overgrote deel van deze derden-leveranciers volledig te goeder trouw betrekkingen onderhoudt met criminele organisaties. De georganiseerde criminaliteit of onderwereld kan niet functioneren zonder deze diensten vanuit de zogenoemde bovenwereld. Ook de publieke sector maakt deel uit van deze voor de georganiseerde criminaliteit zo belangrijke bovenwereld.

Dat de overheid zich zorgen maakt over de invloed van de georganiseerde criminaliteit blijkt uit het beleidsplan (september 1992) voor de aanpak van de georganiseerde criminaliteit in Nederland dat door de toenmalige ministers van Justitie en Binnenlandse Zaken aan de Tweede
Kamer is aangeboden. Zij wijzen op de sterke groei van de georganiseerde criminaliteit en de gevolgen daarvan voor de integriteit en slagvaardigheid van overheidsfunctionarissen. Zij geven daarin aan dat onderzoek naar de activiteiten van criminele organisaties mede wordt bemoeilijkt door het risico van informatielekken ten gevolge van corruptie binnen de overheid. Ook het functioneren van de private sector komt daarbij aan de orde, waarbij de voor het accountantsberoep relevante opmerking wordt gemaakt dat 'financiële. fiscale en juridische experts diensten verlenen aan de georganiseerde criminaliteit'.

\section{Accountant en corruptie}

\subsection{Algemeen}

Het accountantsberoep ontleent zijn sociale functie aan de maatschappelijke behoefte aan zekerheid omtrent de betrouwbaarheid van financiële informatie. Dit stelt eisen aan de mate waarin voor financiële informatie normen zijn ontwikkeld alsmede aan de wijze waarop de accountant zijn controle uitvoert. In landen of sectoren waar corruptie op grote schaal voorkomt, zal een accountant niet zodanig kunnen functioneren dat in de hiervoor genoemde sociale behoefte wordt voorzien. Corruptie leent zich immers niet voor standaardisatie in richtlijnen voor verslaggeving en controle. Uit de auditing standard van het IFAC betreffende Illegal Acts blijkt dit standaardisatieprobleem. Gegeven de grote diversiteit in verschijningsvormen van corruptie zou de praktische toepasbaarheid van de standard gediend zijn met een nadere detaillering.

Dat het accountantsberoep zich zal moeten gaan bezighouden met de corruptieproblematiek is evident; gegeven zijn sociale functie kan de accountant niet voorbijgaan aan corruptie, leidend tot concurrentievervalsing en aantasting van het rechtsstelsel.

Indien de accountant financiële verantwoordingen certificeert waarin de effecten van corruptie zijn opgenomen, zonder dat de accountant daarvan melding maakt aan ten minste de toezichthoudende organen binnen de betrokken organisatie, ondergraaft hij de maatschappelijke betekenis van het beroep.

Ook in zijn adviesfunctie wordt de accountant geconfronteerd met corruptie. De geloofwaardigheid van het beroep is niet gediend met de blijkens 
het beleidsplan van de ministers van Justitie en Binnenlandse zaken bestaande betrokkenheid van accountants bij dienstverlening ten behoeve van criminele organisaties.

\subsection{Onder welke omstandigheden kan het accountantsberoep een bijdrage leveren?}

Corruptie en controlemaatregelen zijn elkaars tegenpolen. In principe betekent deze vaststelling dat de accountant. gegeven zijn deskundigheid op het gebied van preventieve en repressieve controlemaktregelen. een belangrijke inbreng kan hebben bij het voorkomen en bestrijden van corruptic. Het effect van een dergelijke inbreng word bepaald door een antal factoren:

a de omgeving warin de accomtant functioneert;

b de vaktechnische mogelijkheden van de accountant:

c de integriteit van de accountant.

In de analyse van de rol die de accountant kan vervullen in relatie tot corruptie is het van belang vast te stellen dat niet alle bovengenoemde factoren door de accountant kunnen worden beïnvloed. Dit betreft met name de sub a genoemde factor.

\section{Ad a De omgering waarin de accountant finctioneent}

Corruptie houdt niet op bij de landsgrenzen en zal zelf een omgeving zoeken waar imperfecties bestaan in de regulering door de overheid. De bestrijding van corruptie vergt dan ook een internationale aampak waarbij de verschillende overheden zich dienen te verplichten een aantal maatregelen te nemen. Deze maatregelen betreffen:

- De regulering van het economisch leven.

De overheid dient zorg te dragen voor een transparante wetgeving zodat duidelijkheid bestaat over het door de overheid gewenste gedrag val individuen en organisaties. De onderlinge afstemming tussen nationale en supranationale wetgeving is daarbij een belangrijk aandachtspunt. In dit verband zij verwezen naar de uitvoeringsproblemen die voortvloeien uit EC-regelingen op het gebicd van landbouwsubsidies, exportsubsidies en kartels.

Ook zal de overheid zorg moeten dragen voor adequate verslaggevingsstandaarden en een wettelijke basis voor het accountantsberoep. Daarbij zal de overheid er op toe moeten zien dat het accountantsberoep adequate controlestandaarden ontwikkelt.

Een belangrijk element in de verslaggevingsstandaarden betreli de verantwoording van Iransacties met 'related parties": onduidelijkheden omtrent de kring van direct en indirect bij een organisatie betrokkenen kan corruptie vergemakkelijken.

Tevens zal de overheid regels moeten stellen ten aanzien van de organisatie van de kapitaalmarkt: een ondoorzichtige kapitaalmarkt verschaft geen inzicht in de herkomst van financieringsmiddelen die in de private en publieke sectoren worden gebruikt.

Regulering van het economisch leven als bovenbeschreven dient in onderling overleg tussen overheden tot stand te komen.

De overheid zal er geen misverstand over moeten laten bestaan dat corruptie voor haar ten enenmale onatuvaardbaar is: in elk land zal een adequaat systeem van wettelijke regelingen terzake van de opsporing en vervolging van corrupt handelende organisaties en individuen dienen te worden ingevoerd. Gegeven de voortgaande internationalisering van de economische activiteiten zullen eenzijdige maatregelen door individuele overheden in het algemeen weinig elfect sorteren. De Foreign Compt Practices Act (1977) in de Verenigde Staten, welke het verstrekken van steekpenningen aan buitenlandse vertegenwoordigers van bedrijven als economisch delict stratbaar stelt, is hiervan een voorbeeld. De matatschappelijke acceptatie van deze wet is binnen de Verenigde Staten niet groot: vele ondernemingen zien zich beperkt in de mogelijkheden zaken te doen in landen walar steekpenningen onlosmakelijk verbonden lijken met handelstransacties. Daar in deze landen een deugdelijke wetgeving en -handhaving terzake van corruptie ontbreekt, dreigt de Foreign Corrupt Practices Act haar doel voorbij te schieten; juist de ondernemingen uit de Verenigde Staten lijken benadeeld te worden door deze wet die nu juist bedoeld is eerlijke concurrentieverhoudingen te garanderen

- De organisatie binnen de publieke sector.

Als aandachtspunten kunnen worden genoemd:

- Cormuleren van ethische gedragsregels voor overheidsfunctionarissen;

- zorgdragen voor een adequate beloning van overheidsaccountants; 
- opzet van een deugdelijk informatiesysteem op grond waarvan, deels op basis van schattingen, inzicht ontstaat in de omvang en de aard van met het officieuze circuit samenhangende geldstromen. Een dergelijk systeem vergemakkelijkt een gerichte aanpak van verschijnselen als corruptie.

Voor het accountantsberoep zijn deze maatregelen van groot belang; zij creëren een omgeving waarin controle door accountants zinvol is.

\section{Ad $b$ De vaktechnische mogelijkheden van de} accountant

Corruptie zal met name optreden in situaties waarin samenspanning tussen functionarissen van meerdere organisaties plaatsvindt. Kenmerkend voor samenspanning is dat de betrokkenen bij voorkeur geen registraties voeren van deze activiteiten. Registraties zijn evenwel van groot belang voor de effectiviteit van accountantscontrole.

Een belangrijk controlemiddel van de accountant betreft het verkrijgen van inlichtingen van de gecontroleerde. De accountant verkeert in een niet benijdenswaardige positie indien de gecontroleerde corrupt handelt.

De noodzaak van een gedegen beoordeling door de accountant van de aanvaardbaarheid van opdrachten en de integriteit van opdrachtgevers wordt hiermee onderstreept. In deze beoordeling dient hij aandacht te besteden aan de aard van de bedrijfsactiviteiten, de doorzichtigheid van eigendomsverhoudingen. de wijze van financiering en de attitude van de opdrachtgevers ten opzichte van interne en externe controle. Ook na aanvaarding van een opdracht is het voor de accountant van belang regelmatig na te gaan in hoeverre veranderingen binnen of in de omgeving van de te controleren organisatie de integriteit van de opdrachtgever en de gecontroleerde hebben aangetast.

\section{Ad c De integriteit van de accountant}

De openbare accountant heeft een direct financieel belang bij de verwerving van winstgevende opdrachten. De concurrentie op de accountancymarkt kan een bedreiging vormen voor integriteit van de accountant. Dit kan zich uiten in een minder diepgaand onderzoek naar de aanvaardbaarheid van opdrachten, maar ook in de wijze waarop de accountant zich opstelt ingeval hij wordt geconfronteerd met corrupt handelen van de gecontroleerde. De accountant moet immers sterk in zijn schoenen staan indien een belangrijke opdrachtgever informatie omtrent een kleinere relatie van de accountant wenst en daarbij dreigt met een heroverweging van de opdracht aan de betreffende accountant.

Uitgangspunt in dit artikel is dat corruptie negatieve maatschappelijke effecten veroorzaakt; het economisch bestel raakt ontwricht en corrupt handelen leidt tot concurrentievoordelen voor corrupte ondernemers. Maar ook accountants die meewerken aan corruptie of gedogen dat hun opdrachtgevers corrupt handelen bereiken, zouden een concurrentievoordeel kunnen realiseren ten opzichte van collega's die dergelijke werkzaamheden afwijzen.

Het nastreven door individuele accountants en accountantsmaatschappen van omzetmaximalisatie op korte termijn, zonder daarbij aandacht te besteden aan de aanvaardbaarheid van de opdracht en de integriteit van opdrachtgevers zal niet alleen een rol van de accountant in de bestrijding van corruptie in de weg staan; de maatschappelijke functie van het beroep wordt aangetast.

In de agency-theorie wordt hier voor de beroepsorganisatie een belangrijke taak aanwezig geacht; zij dient te zorgen voor een adequate tuchtrechtspraak en bescherming van de fungerend accountant door regels te stellen voor wisselingen van accountants bij organisaties. Dit is echter niet voldoende: de individuele accountant dient op basis van integriteit zijn functie uit te willen oefenen.

De accountant mag niet alleen staan in een zorgvuldige beoordeling van de integriteit van zijn opdrachtgever; alleen wanneer bankiers. advocaten en notarissen samen met accountants een blok vormen tegen corrupte opdrachtgevers kan sprake zijn van een effectieve bestrijding van corruptie.

De hiervoor genoemde begrenzingen betreffen met name de detectie door accountants van corruptie. Daarbij dient nog te worden opgemerkt dat detectie van corruptie, zeker ingeval daarbij de georganiseerde criminaliteit is betrokken, niet door accountants alleen kan worden uitgevoerd.

De accountant beschikt echter ook over kennis van, interne, controlesystemen, welke kennis van groot belang kan zijn voor de preventie van corruptie. Als adviseur van overheden en private ondernemingen zal de accountant op het gebied van corruptiepreventie een belangrijke rol kunnen spelen. 


\subsection{Aandachtsgebieden vor de accountant}

\subsection{Algemeen}

De terreinen waarop de accountant een bijdrage kan leveren in de bestrijding van corruptie kunnen worden onderverdeeld naar de volgende sectoren:

- overheid:

- bedrijtsleven.

Hierna volgt een opsomming van werkzaamheden die de alccountant binnen de onderscheiden sectoren zou kunnen uitvoeren. De nadruk zal daarbij liggen op de publieke sector.

\subsubsection{Orerheid}

De overheid ziet zich in de bestrijding van corruptie geconfronteerd met een Iweetal aandachtsgebieden, de eigen organisatie en de private sector.

In het voorgaande is cen viertal raakvlakken tussen publieke en private sector genoemd waar. gegeven het grote financiële belang. het risico van corruptie grool lijkt te zijn. Deze raakvlakken betreffen belastingen, subsidies, overheidsinvesteringen en concessies. Ten aanzien van deze raakvlakken zijn de volgende aandachtspunten voor corruptiepreventie te noemen.

\section{Belastingen en subsidies:}

- voordat een regeling wordt ingevoerd moet worden nagegaan of naleving ervan controleerbatar is:

- de voorgeschreven inhoud van accountantsverklaringen bij subsidie-afrekeningen dient te worden afgestemd met de accountantsorganisatie. Interpretatieproblemen kunnen op deze wijze worden voorkomen:

- bepaalde economische activiteiten worden gesubsidieerd door meerdere overheidsinstellingen. Het informatiesysteem binnen de overheid dient zodanigg te zijn dat centralal inzicht bestaat in mogelijke overlappingen van subsidieverstrekkingen door de verschillende overheidsinstellingen. Een dergelijk informaliesysteem dient in vele landen nog te worden geïmplementeerd.

\section{Overheidsinvesteringen:}

- formuleren van specificalties waaraan het te leveren object dient te voldoen:

- procedures voor hel alanvragen van offertes:

- procedures voor de bewaking van de kosten van uitvoering van openbare werken;

- functieroulatie.

\section{Concessies:}

Kenmerkend voor de verlening van concessies is in het algemeen dat enerzijds de financiële belangen voor concessiehouders groot zijn. terwijl anderzijds het aantal overheidsfunctionarissen betrokken bij de verstrekking van concessies klein is. De concessievoorwaarden dienen duidelijk geformuleerd te worden, vooral ten aanzien van de wijze walarop door concessiehouders gedurende de looptijd verantwoording wordt afgelegd. Ook daarbij is de controleerbaarheid van de verantwoording een belangrijk punt.

In het algemeen kan nog worden opgemerkt dat de overheid zorg moet dragen voor adequate informaliesystemen: ten aanzien van subsidies is in het voorgalande al het een en ander opgemerkt. De registraties binnen de overheidssector kenmerken zich in verschillende landen door achterstanden in de registratie van de werkelijke gang van zaken. onvoldoende analyse van verschillen tussen begrolingen en werkelijkheid alsmede een grote nadruk op detailinformatie, waardoor een totaalinzicht in de fïnanciële gang van zaken wordt belemmerd.

Bovenstaande maatregelen en aandachtspunten met betrekking tot raakvlakken tussen publieke en private sector lenen zich voor advieswerkzaamheden door accountants. De opsomming betreft aspecten van preventief gerichte controle.

De accountant kan, gebruik makend van zijn kennis van controlesystemen, ook in het kader van opsporing van corruptie een bijdrage leveren. Gegeven de beperkte middelen waarover Justitie en politie kunnen beschikken is het voor hen van belang inzicht te krijgen in de corruptiegevoeligheid van branches. Ook de mogelijkheid van infiltratie door de georganiseerde criminaliteit is daarbij relevant. De accountant kan behulpzaam zijn bij het ontwikkelen van een analysemethode op het niveau van bedrijfstakken. In een dergelijke analyse dient aandacht te worden besteed aan zaken als:

- economische ontwikkelingen binnen de bedrijlstak:

- mate van regulering door de overheid en de invloed daarvan op de bedrijfsvoering: usances in de bedrijfstak (aard betalingsverkeer, wijze waarop opdrachten worden verkregen. onderlinge verrekeningen tussen participanten in een bedrijfstak).

Op basis van een dergelijke analyse ontstaat een eerste indruk omtrent de mogelijkheden van corruptie binnen de betreffende bedrijfstak. 
Een volgende stap is een analyse op het niveau van individuele ondernemingen. Daarbij komen de volgende elementen aan de orde:

- transparantie van juridische structuur en eigendomsverhoudingen;

- rationaliteit van financiering en resultaatontwikkeling (indicatoren voor zogenoemde witwasactiviteiten);

- beheersingsmaatregelen getroffen door de leiding van de onderneming.

\subsubsection{Bedriffsleven}

De in de vorige paragraaf beschreven analyse op het niveau van bedrijfstak en individuele ondernemingen komt bij de uitvoering van een opdracht tot controle van een jaarrekening steeds aan de orde; het verschil betreft in het algemeen de mate van diepgang.

Materiële financiële gevolgen van corruptie voor de te controleren verantwoording zullen voor de accountant aanleiding moeten zijn nader onderzoek te verrichten naar oorzaak en omvang van het geconstateerde geval van corruptie.

In zijn risico-analyse voorafgaand aan de uitvoering van zijn controle dient de accountant zich bewust te zijn van een merkwaardige eigenschap van het verschijnsel corruptie. In het algemeen zal corrupt handelen door de leiding niet in het belang zijn van een grote groep van belanghebbenden bij een onderneming (aandeelhouders, bankiers en werknemers). Voorbeelden van deze vorm van corruptie zijn: omkoping van de leiding door leveranciers en transacties met ondernemingen waarin de leiding financiële belangen heeft. In al deze gevallen verrijkt de leiding van het bedrijf zich ten koste van genoemde belanghebbenden. Er bestaan echter ook vormen van corruptie die voor deze belanghebbenden op zich alleen maar voordelen lijken te hebben. Verwerving van grote opdrachten door omkoping van functionarissen in dienst van belangrijke afnemers en dienstverlening ten behoeve van criminele organisaties zijn voorbeelden van dit aspect van corruptie.

Deze problematiek brengt met zich mee dat de accountant in zijn risico-analyse rekening moet houden met beperkingen in de waarde van binnen de onderneming aanwezige monitoringcontrols, gericht op de preventie van corruptie. Dit ontslaat de accountant overigens niet van zijn plicht de ondernemingsleiding te adviseren omtrent de implementatie van dergelijke monitoringcontrols. Overigens zullen vormen van corruptie die ook het economisch belang van direct bij de onderneming betrokkenen dienen, vaak optreden bij ondernemingen waarvan de resultaten onder druk staan. De accountant zal hiermee niet alleen op het moment van acceptatie van een opdracht rekening moeten houden; regelmatig dient een accountant na te gaan of opdrachten gecontinueerd dienen te worden. Hierbij zal hij de ontwikkeling in de economische positie in relatie tot de mogelijkheid van corrupt handelen in beschouwing dienen te betrekken.

Met betrekking tot de aanpak van corruptie in het bedrijfsleven is het van belang te wijzen op een ontwikkeling in de Verenigde Staten. De New York State Organized Crime Task Force heeft recentelijk het Certified Investigative Auditing Firm Program ontwikkeld. In het kader van dit programma, gericht op de bestrijding van corruptie en georganiseerde criminaliteit, wordt gebruik gemalkt van de diensten van Certified Investigative Auditing Firms (CIAF’s). Deze bureaus waarin kennis van accountancy, techniek en andere disciplines zijn vertegenwoordigd, voeren onderzoeken uit naar de mate waarin ondernemingen opereren binnen het kader van de relevante wettelijke voorschriften. Ook de binnen een onderneming expliciet geformuleerde ethische normen worden in het onderzoek betrokken. Inschakeling van een CIAF is overigens verplicht wanneer is vastgesteld dat een onderneming zich schuldig heeft gemaakt aan onwettig of onethisch handelen. Afhankelijk van de uitkomsten van het onderzoek wordt aan de ondernemingen een kwaliteitskeurmerk verleend.

Gelet op het maatschappelijk belang van corruptie zou het aanbeveling verdienen ook in Nederland de wenselijkheid van een dergelijk kwaliteitskeurmerk te onderzoeken.

Daarbij zou ook de effectiviteit van het toezicht door de Raad van Commissarissen van de te certificeren ondernemingen in het onderzoek dienen te worden betrokken.

\section{Conclusie}

Corruptie treedt over de gehele wereld op. Een internationale aanpak van de bestrijding van corruptie is gewenst. Daartoe zullen in eerste instantie normen dienen te worden vastgesteld voor de wijze waarop de verschillende overheden maatregelen nemen gericht op de preventie van corruptie. Deze maatregelen betreffen zowel de 
publieke als de private sector. Het accountantsberoep kan daarbij een zinvolle bijdrage leveren.

Indien tegelijkertijd door het accountantsberoep bij de uitoefening van controlewerkzalamheden bij individuele organisaties aandacht wordt besteed aan de attitude binnen deze organisaties ten aanzien van corruptie zal dit in een tweetal opzichten maatschappelijke voordelen opleveren. Enerzijds wordt immers de overheid gesteund in haar strijd tegen corruptie, terwijl anderzijds de maatschappelijke functie van de accountant aan betekenis wint.
Dassen, R.J.M., (1989), De Leer van het Gewekte Vertrouwen: Agency avant la Lettre?. Maandblad voor Accountancy en Bedriifseconomie.

Jansman, A.J.E., (1992), The Integrity of the Profession, paper Fifth International Anti Corruption Conference, Amsterdam.

Manen, J.A. van, (1992), Fighting Corruption: What can Accountants do?, paper Fifth International Anti Corruption Conference, Amsterdam

Scott, J.C., (1972), Comparative Political Corruption, Englewood Cliffs

Supojo, S., (1972), Een Research Design van de Indonesische Accountant in de Bestrijding van Corruptie, Maandblad voor Bedriffsadministratie en Bedriffsorganisatie

\section{N 0 O T}

1 De schrijver dankt M. van Dijk en J.A. van Manen voor hun waardevolle opmerkingen bij een eerdere versie van dit artikel. 